Indexed by

\title{
Scopus
}

\section{DEVELOPMENT OF METHODS FOR ASSESSING THE SAFETY OF LIGHT HYDROCARBON STORAGE FACILITIES IN EMERGENCY SITUATIONS}

Crossref

KOBSON

Industrial University of Tyumen, Department of Technosphere Security, Tyumen, Russian Federation

\author{
Mikhail V. Omelchuk \\ Industrial University of \\ Tyumen, Department of \\ Technosphere Security, \\ Tyumen, Russian Federation
}

Key words: air stagnation zones, safety, modelling, computational fluid dynamics, light hydrocarbons doi:10.5937/jaes0-30779

Cite article:

N. Permyakov V., V. Omelchuk M. (2022) DEVELOPMENT OF METHODS FOR ASSESSING THE SAFETY OF LIGHT HYDROCARBON STORAGE FACILITIES IN EMERGENCY SITUATIONS, Journal of Applied Engineering Science, 20(1), 71 - 78, DOI:10.5937/ jaes0-30779

Online aceess of full paper is available at: www.engineeringscience.rs/browse-issues 


\title{
DEVELOPMENT OF METHODS FOR ASSESSING THE SAFETY OF LIGHT HYDROCARBON STORAGE FACILITIES IN EMERGENCY SITUATIONS
}

\author{
Vladimir N. Permyakov*, Mikhail V. Omelchuk \\ Industrial University of Tyumen, Department of Technosphere Security, Tyumen, Russian Federation
}

The risk of accidents involving light hydrocarbons is caused by the physicochemical properties of the components, primarily propane and butane. The most catastrophic accidents involving these substances were on November 19, 1984, in the city of San Juan Ixhuatepec (Mexico) and on June 4, 1989, on the Asha - Ulu-Telyak section (USSR), in each of which more than 500 people died. The novelty of the study is determined by the requirement to ensure industrial and fire safety of storage facilities for light hydrocarbons by predicting probable zones of air flow stagnation. The authors calculated the formation of probable air stagnation zones for various space-planning solutions by using a three-dimensional modelling system and the finite volume method. The paper developed a methodology for assessing the safety of storage facilities for light hydrocarbons in emergency situations, which is based on the analysis of probable air stagnation zones by using three-dimensional modelling systems. The practical significance of the study is determined by the additional development of a parameter for assessing the safety state of a storage facility for light hydrocarbons (Ks) and a resulting parameter (Kr) for calculating the optimal location of structures and their structural changes. Integration of stagnation zone sizes into a single formula with the results of other safety calculations is an urgent scientific and applied problem.

Key words: air stagnation zones, safety, modelling, computational fluid dynamics, light hydrocarbons

\section{INTRODUCTION}

Light hydrocarbons are found in oils, natural combustible gases, and gases from petroleum refining [1]. These include hydrocarbons with carbon content in the C1-C6 range [2] and are a mixture of the alkane class hydrocarbons [3]. Light hydrocarbons of different fractional composition are stored in reservoirs both in "pure" form and in a mixture with other additives [4]. Substances such as methane and ethane are rarely stored, mostly transported to consumers immediately after extraction [5]. In connection with this fact and low values of the gas phase density, the storage facilities for methane and ethane were not considered in the paper [6]. Liquefied petroleum gas (LPG) and natural gas liquids (NGLs) contain significant proportions of light hydrocarbons (C3-C6) [7]. One of the tasks solved by numerical modelling is the search for probable air stagnation zones (areas where the air flow (wind) speed does not exceed $0.5 \mathrm{~m} / \mathrm{s}$ ) in the territory of hazardous industrial facilities (HIF) [89]. Options for solving this problem were considered by scientists R.R. Tlyasheva, A.V. Solodovnikova, N.N. Krasnogorskaya, V.V. Akhmerov, who used the method of predicting probable air stagnation zones using a three-dimensional modelling system. Such studies are of particular importance for objects containing light hydrocarbons (C3-C6) [10], which is explained by the physicochemical properties of the latter [11]. Reducing the size of stagnation zones can significantly reduce the volume of the cloud of the fuel-air mixture and, as a result, reduce the explosion and fire hazard of the object [12].

\section{MATERIALS AND METHODS}

Currently, there are no studies on detailed investigation of air stagnation zones for tank batteries on the territory of gas filling stations and gas processing plants [13]. At the same time, in the current regulations at the stage of hazard identification and search for optimal options for the location of the production site [14], the location of technological facilities, the layout of installations and equipment, there is no method for a comprehensive assessment of probable stagnation zones using three-dimensional modelling systems. This method allows to choose the most effective solution to ensure the safety of light hydrocarbons storage facilities [15]. Therefore, there is a need to develop a methodology that provides for the solution not only of this problem, but also the introduction of individual space-planning changes with their mandatory testing in order to reduce the probability of air blanketing [16], which, in turn, can increase the industrial and fire safety of storage bases for light hydrocarbons and adjacent territories [17].

The paper presents a developed methodology and an algorithm for it, which make it possible to carry out a comprehensive assessment of stagnation zones using three-dimensional modelling systems and select the most effective safety solution. The proposed method makes it possible to predict probable stagnation zones for objects, taking into account the meteorological conditions of the location and provides for an increase in their safety, including due to volume-planning changes at all stages of the object's life cycle. The developed methodology for assessing the safety of light hydrocarbon stor- 


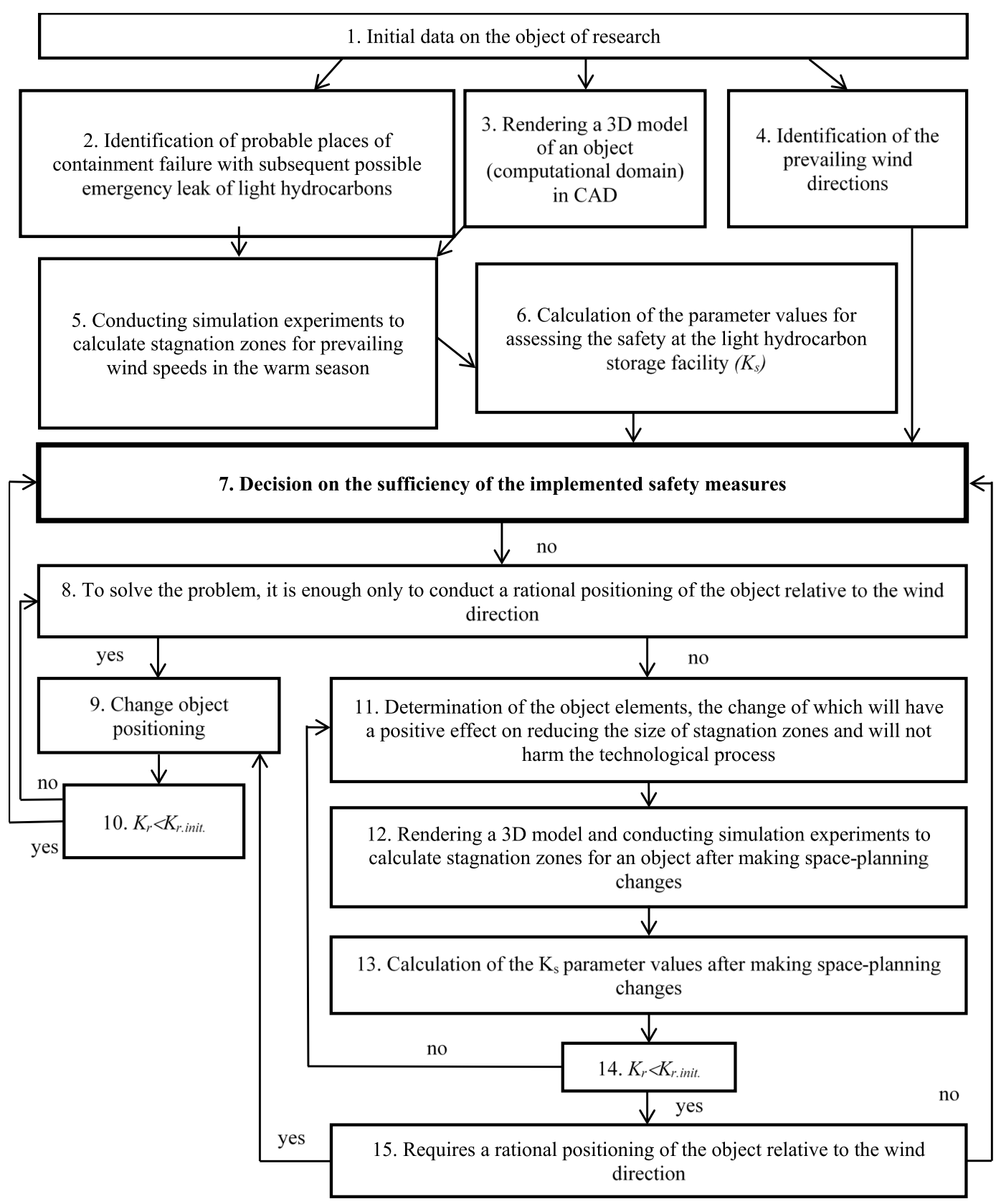

Figure 1: Algorithm for assessing the safety at light hydrocarbon storage facilities

age facilities and the algorithm for it are based on the findings obtained in previous author's studies [18-19], and tested for the object of modelling (LPG tank farm) (Figure 1).

Stage 1. Initial data on the research object. To conduct research, the following initial data is required:

- general plan of the object and the adjacent territory;

- topography of the terrain;

- information about the number of employees of nearby organisations, the potential danger of nearby industries, the number of people living nearby;

- dimensions, shape of all structures of the object;

- location of structures relative to each other;

- basic technological operations at the facility;

- frequency of wind directions in the warm season for

\section{a given territory;}

- wind speed in the warm season for a given territory; - characteristics of ignition sources at the facility and the likelihood of their occurrence.

\section{RESULTS AND DISCUSSION}

To test the developed methodology, an LPG storage (LPGS) was chosen, which is one of the widespread facilities that store a large number of light hydrocarbons [20]. The presence of significant (up to several hundred tons) gas reserves at the LPGS and the high potential hazard of the substance make it possible to classify the LPGS as a hazardous production facility that can pose a threat not only to personnel, but also to the population [21]. The main technological operations at the LPGS are loading and unloading operations associated with 
receiving and supplying liquefied petroleum gas (LPG) to consumers [22]. The movement of the streams of the liquid and gaseous phase is carried out by creating overpressure with the help of compressors in a railway tank car or tank. The discharge of LPG from railway tanks into the tanks of the storage facility (if the former are above the level of the latter) occurs through the discharge posts by gravity and under gas pressure. Autogas carriers are filled with a compressor, which extracts vapours from the tanker to the storage tank. As a result, the pressure in the tank increases and liquefied gas is poured into the road tanker. LPG is pumped through gas pipelines. Each tank contains LPG in a liquid and gaseous (steam) form simultaneously. LPG is contained at ambient temperature at a pressure of 1.6 MPa (maximum).

Stage 2. Identification of probable places of containment failure with subsequent possible emergency leak of light hydrocarbons. As part of this stage, it is necessary to consider the possible causes of emergencies at the facility, to consider the accident scenarios, including the most probable and most dangerous. On the territory of the storage facility under consideration, depressurisation is possible in the tank farm, at railway drain posts, autogas carriers filling station, in the cylinder filling workshop, pumping and compressor equipment, pipelines (Figure 2). The most important is the search for probable stagnation zones in the technological zone of the facility, which includes tanks for storing light hydrocarbons.

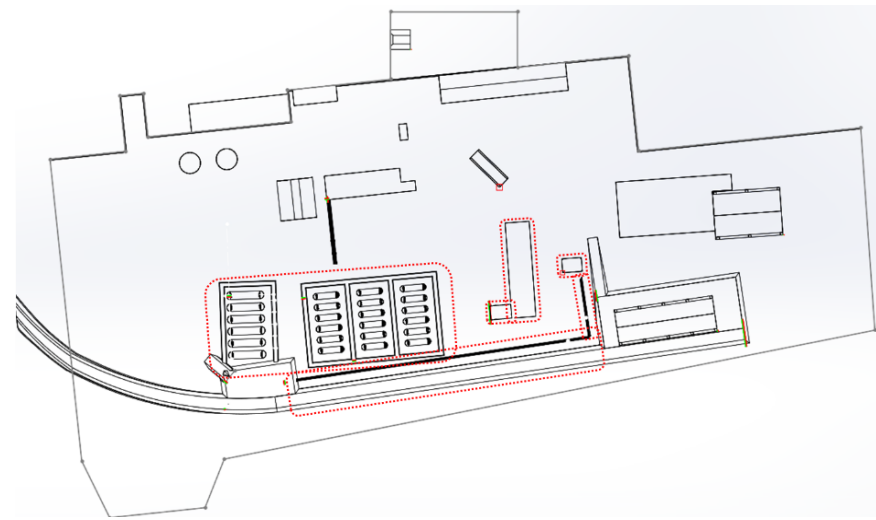

Figure 2: Zones of possible emergency leak of LPG

Stage 3. Rendering a 3D model of an object (computational domain) in CAD. When creating a three-dimensional model, single-running small diameter pipelines (200 mm or less) can be ignored. This assumption does not affect the result, since the parameters of such pipelines do not allow the creation of stagnation zones of a significant size. An example of a three-dimensional model of the tank storage is shown in Figure 3.

Stage 4. Identification of the prevailing wind directions. The prevailing wind directions are those in which the greatest human and material losses are possible. To implement this stage, information is needed about nearby organisations, the potential danger of nearby industries and the number of people living nearby.

Stage 5. Conducting simulation experiments to calculate stagnation zones for prevailing wind speeds in the warm season. When carrying out simulation experiments, taking into account the physicochemical properties of light hydrocarbons, it is necessary to determine the probable air stagnation zones at a height of $0.2 ; 0.5 ; 1.5 \mathrm{~m}$ at wind speeds prevailing in the warm season on the territory of the facility. Examples of visualisation of air flows and stagnation zones are shown in the Figure 4.



Figure 3: Three-dimensional model of a tank farm and a railway overpass on the territory of the LPGS


Figure 4: An example of air flows and stagnation zones visualisation

According to the results of simulation experiments, depending on the direction of the wind and the height of measurements, the sizes of stagnation zones are found. It also reveals which wind directions correspond to the maximum and minimum areas of probable stagnation zones. To calculate the parameters of stagnation zones, the FlowVision software package was used, which is based on the finite volume method. The simulation used a rectangular adaptive locally refined mesh (Figure 5). The results of the studies on the dependence of probable stagnation zone size on the direction and wind speed for three different heights are shown in the Figure 6.

It is recommended to calculate the mass of evaporated light hydrocarbons taking into account the functional dependence proposed in the previous studies by the authors [18, 19]:

$m(t)=m_{0} \cdot\left(a_{0}+a_{1} \cdot\left(\frac{\Delta t}{t_{k}}\right)^{-0,01}+a_{2} \cdot e^{-\frac{\Delta t}{t_{k}}}\right)$ 


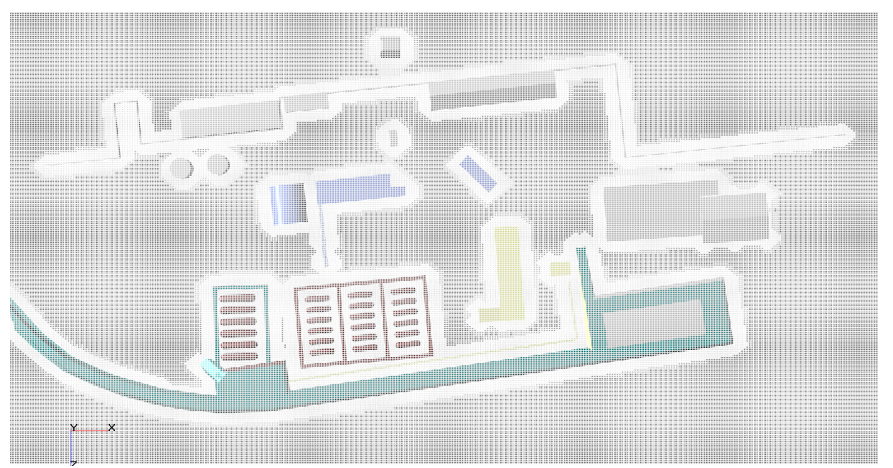

Figure 5: Example of a locally refined mesh at a height of $0.2 \mathrm{~m}$

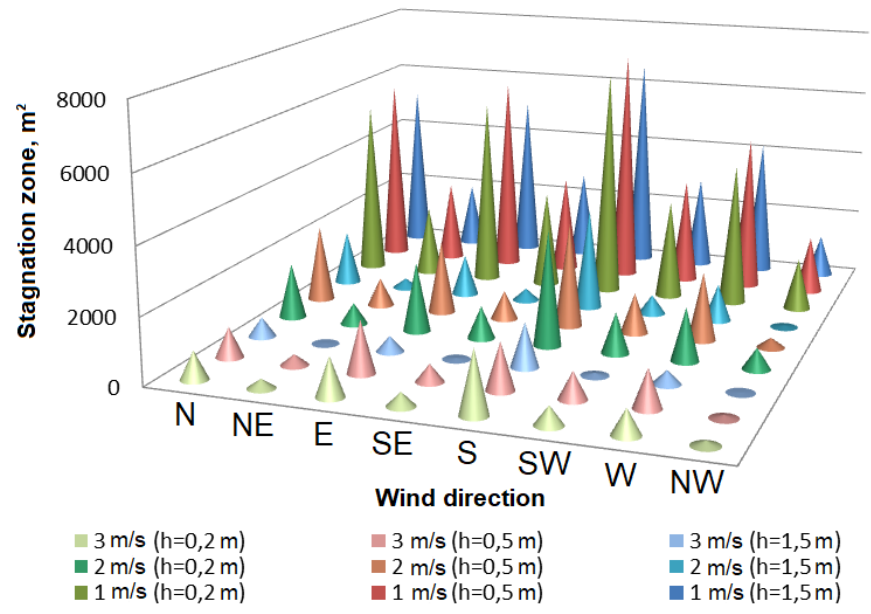

Figure 6: Dependence of the size of probable stagnation zones on the direction and speed of the wind at different heights

where $\mathrm{m}(\mathrm{t})$ - mass of the substance evaporated from the beginning of the leak until the moment of time $\mathrm{t}, \mathrm{kg} ; \mathrm{m}_{\mathrm{o}}$ - initial mass of the substance, kg; $a_{0}, a_{1}, a_{2}$ - estimated coefficients (the value of estimated coefficients for some storage temperatures Tst and ambient temperatures $T_{a m b}$ are presented in [18-19]; $\Delta \mathrm{t}-$ time elapsed since the moment of leak, $s ; t_{k}$ is the time, elapsed from the moment of leak to the limit of the functional dependence applicability, $s\left(t_{k}=3600\right)$.

Stage 6. Calculation of the parameter values for assessing the safety at the light hydrocarbon storage facility. Taking into account the fact that the safety of an object is directly proportional to the probability of an ignition source on the path of cloud propagation and the area of stagnation zones, a parameter for assessing the safety state of a light hydrocarbon storage facility for the wind direction (WD) $X$ has been developed, which can be used as a comparative criterion (Eq. 2, 3). A decrease in the parameter values will indicate an increase in the safety of the object in emergency situations.

$$
\begin{aligned}
& K_{s}(W D)=\frac{P(W D) \cdot S_{S . z .} \cdot\left(1-\prod_{i=1}^{\prime} \prod_{n-1}^{N}\left[1-Q_{i}\left(I S_{n} / C M\right)\right]\right)}{S_{t . f .}} \\
& K_{s}(W D)=\frac{P(W D) \cdot S_{s . z .} \cdot\left(1-\prod_{i=1}^{\prime} \prod_{n-1}^{N}\left[1-Q_{i}\left(H S_{n}\right) \cdot Q_{i}\left(I_{n}\right)\right]\right)}{S_{t . f .}}
\end{aligned}
$$

where $P(W D)$ - probability of occurrence of the $X$ wind direction; $S_{\text {s.z. }}$ - area of stagnation zones at wind direction


ry structures minus the area of equipment, buildings and structures, $\mathrm{m}^{2} ; \mathrm{Q}_{\mathrm{i}}\left(\mathrm{IS}_{\mathrm{n}} / \mathrm{CM}\right)$ - conditional probability of the occurrence of a cloud of fuel-air mix on the path of propagation in the i-th element of the object of the n-th ignition source capable of igniting a combustible medium; $Q_{i}\left(H S_{n}\right)$ - probability of the occurrence of the $n$-th heat source in the i-th element of the object during the year; $Q_{i}\left(I_{n}\right)-$ conditional probability that the ignitibility of the object of the $\mathrm{n}$-th heat source appearing in the i-th element is sufficient to ignite the combustible medium in this element.

It is advisable to calculate the probability of a wind in a certain direction based on long-term statistical data for the warm season in the area under consideration. It is recommended to calculate the areas of probable stagnation zones at heights of $0.2,0.5$ and $1.5 \mathrm{~m}$ at the lowest of the air flow rates typical for the warm season of the certain territory. To calculate the developed parameter Ks, it is necessary to take the largest of the calculated values of the stagnation zone area. When calculating the Ks parameter, the conditional probability of the appearance of a fuel-air cloud in the i-th element of a heat source capable of igniting a combustible medium is recommended to be made based on available methods or to take ready-made values from the scientific literature. The main intermediate values for calculating the probability of an ignition source occurrence are presented in the Table 1.

Table 1: Main intermediate values for calculating the probability of an ignition source occurrence

\begin{tabular}{|c|c|}
\hline Designation & Parameter name \\
\hline$Q\left(\mathrm{TS}_{1}\right)$ & $\begin{array}{c}\text { Probability of occurrence of atmo- } \\
\text { spheric electricity discharge }\end{array}$ \\
\hline $\mathrm{Q}\left(\mathrm{TS}_{2}\right)$ & $\begin{array}{c}\text { Probability of occurrence of an electrical } \\
\text { spark }\end{array}$ \\
\hline $\mathrm{Q}\left(\mathrm{TS}_{3}\right)$ & Probability of occurrence of frictional spark \\
\hline $\mathrm{Q}\left(\mathrm{TS}_{4}\right)$ & $\begin{array}{c}\text { Probability of occurrence of open } \\
\text { flames and sparks }\end{array}$ \\
\hline $\mathrm{Q}\left(\mathrm{TS}_{5}\right)$ & $\begin{array}{c}\text { Probability of occurrence of elements } \\
\text { heated above the permissible temperature }\end{array}$ \\
\hline
\end{tabular}

In turn, each of these parameters requires detailed analysis and determination of additional values. The calculation data of the $\mathrm{K}_{\mathrm{s}}$ parameter for the considered LPGS are presented in Figure 7 and in the Table 2.

The calculation data shows that the highest parameter value was obtained for the southward wind due to a combination of various factors. In this regard, when making space-planning and organisational and technical changes, the greatest attention should be paid to the southward wind.

Stage 7. Decision on the sufficiency of the implemented safety measures. This stage is the final one for the process of assessing the safety of LPGS. If it is possible to decide on the sufficiency of the implemented safety 


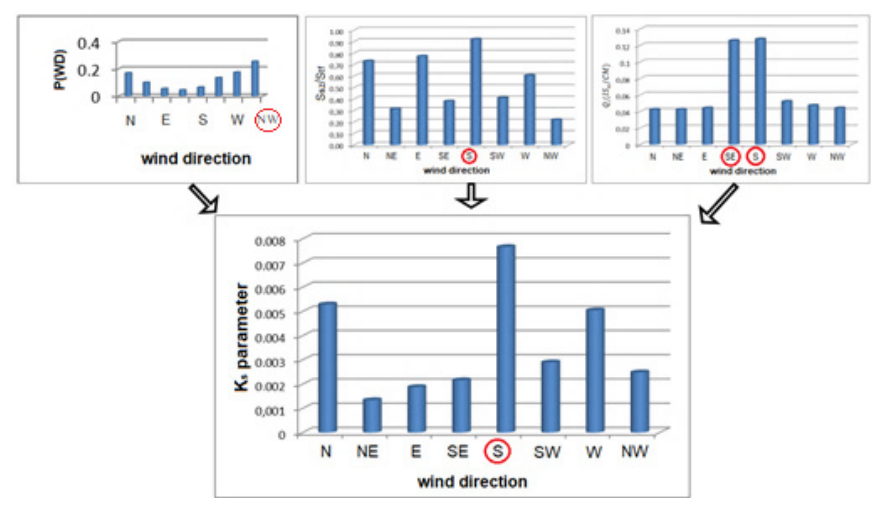

Figure 7: The calculation data of the $K_{s}$ parameter for LPGS

Table 2: An example of the calculation data of the $K_{s}$ parameter

\begin{tabular}{|c|c|}
\hline Designation & Parameter value Ks \\
\hline $\mathrm{K}_{\mathrm{s}}(\mathrm{N})$ & 0.00529 \\
\hline $\mathrm{K}_{\mathrm{s}}(\mathrm{NE})$ & 0.00134 \\
\hline $\mathrm{K}_{\mathrm{s}}(\mathrm{E})$ & 0.00188 \\
\hline $\mathrm{K}_{\mathrm{s}}(\mathrm{SE})$ & 0.00216 \\
\hline $\mathrm{K}_{\mathrm{s}}(\mathrm{S})$ & 0.00766 \\
\hline $\mathrm{K}_{\mathrm{s}}(\mathrm{SW})$ & 0.00290 \\
\hline $\mathrm{K}_{\mathrm{s}}(\mathrm{W})$ & 0.00505 \\
\hline $\mathrm{K}_{\mathrm{s}}(\mathrm{NW})$ & 0.00249 \\
\hline
\end{tabular}

measures for the object in its existing version, then the remaining stages are not necessary. Otherwise, activities are required, the ultimate goal of which is to make such a decision.

Stage 8. There are two main ways to reduce air stagnation zones on the site: 1) the rational positioning of the object relative to the wind direction; 2) making space-planning changes. If the problem of significant sizes of stagnation zones can be solved only by rational positioning of the object, proceed to the implementation of stage 9. In other cases - to stage 11. For the LPGS under consideration, it is not possible to solve the problem of increasing safety only by rational positioning of the object relative to the wind rose, so it is necessary to make changes to the elements of the object (stages of the algorithm No. 11, 12).

Stage 9. Change object positioning. When choosing a rational positioning of the object due to the location of light hydrocarbon storage facilities relative to the prevailing wind directions, it is possible to reduce the likelihood of gas contamination in general or for the direction considered. The rational positioning of the object relative to the wind direction can only reduce the frequency of occurrence of stagnation zones of significant size, but does not affect their size and, in this case, will not give the desired effect in improving the safety of the object. Therefore, in order to reduce the size of potential areas of accumulation of substance released, it is necessary to make possible space-planning changes in the design documentation at the design stage. For cases where the problem of stagnation zones is solved by the rational placing of the object, it is necessary to abide the rule: the most prevalent wind directions, from the standpoint of possible human casualties, should correspond to the smallest $\mathrm{K}_{\mathrm{s}}$ parameter value.

Stage 10. Potentially, situations are possible when the changes introduced lead to a decrease in the parameter value Ks at some wind directions, but at the same time contribute to an increase in the parameter values $\mathrm{Ks}$ at other wind directions. To solve this problem, it is proposed to use the resulting parameter for assessing the safety state of the facility as a test value (4).

$K_{r}=\frac{\sum_{i=1}^{n} K_{S i}(W D)}{n}$

where $K_{\mathrm{si}}(W D)$ - parameter for assessing the safety state of a light hydrocarbon storage facility at a certain wind direction; $\mathrm{n}$ - the number of considered wind directions $(n=8 ; 16)$. At stage 10 , a check is carried out as to how the changes made affect the safety of the object as a whole by comparing the resulting parameter values before $\left(\mathrm{K}_{\text {r.init. }}\right)$ and after $\left(\mathrm{K}_{\mathrm{r}}\right)$ changes in the object's positioning

Stage 11. Determination of the elements of the object, the change of which will have a positive effect on reducing the size of stagnation zones and will not harm the technological process. In order to reduce the area of potential zones of accumulation of substances released, it is possible to make possible space-planning changes at the design stage. For LPGS facilities, a hypothesis has been put forward that a reduction in the size of stagnation zones can be achieved by introducing space-planning changes associated with the following elements: 1) railway embankment; 2) tank farm; 3) buildings located in the direction of air masses movement.

Stage 12. Rendering of 3D model, simulation experiments to calculate stagnation zones for an object after making space-planning changes. Creation of a three-dimensional model and conducting simulation experiments at this stage should be carried out similarly to Stage 3 and 5 . In the process of their implementation, both the space-planning changes separately, and options for their combination should be considered. Within the framework of the hypothesis indicated at Stage 11, a number of space-planning changes for the considered LPGS were modelled. Six options for making space-planning changes, as well as their combination were considered. In total, 13 different variants of territory planning were analysed, for each of which computational experiments were carried out.

The first change that was studied was the location of the railway embankment, which has a height of $2.5 \mathrm{~m}$ and a length of about $300 \mathrm{~m}$ on the site (including the length of the embankment under the cold storage warehouse, which is an inseparable continuation of the railway embankment). The embankment is equipped with two ramps: the first is located near tanks with a volume of 
$100 \mathrm{~m}^{3}$; the second is near the road tanker filling station. An embankment with a railway dead end, an embankment under a cold warehouse and two ramps are a single structural element, so all manipulations with them were carried out conjointly. The following assumption was put forward: if the railway embankment was moved further from the tank farm, then due to this it will be impossible to reduce the size of the air stagnation zones. Computational experiments were carried out with a step of displacement of the embankment equal to $2.5 \mathrm{~m}$. Due to the fact that the largest zones of stagnation are created with the southward wind (when the wind flow is transversal to the railway embankment), all computational experiments related to changing the layout of the object were carried out for a given wind direction with speed of $1 \mathrm{~m} / \mathrm{s}$. Results are displayed for a height of $1.5 \mathrm{~m}$.

In the absence of the possibility of making space-planning changes (for example, the facility is already in operation), then the level of safety can be increased through a number of other measures. For example, a rational arrangement of gas analysis sensors or additional diagnostic systems of normal and dangerous states of technical objects, which will reduce the likelihood of unacceptable defects, reveal a thinning of the wall or possible uneven load on the supports. In combination with technical measures, it is necessary to carry out organisational measures aimed at reducing the likelihood of an ignition source appearing on the route of the fuel-air mix cloud.

Stage 13. Calculation of the Ks parameter values after making space-planning changes. The calculation should be done in the same way as in Stage 6 for each space-planning change made. Figure 8 shows the results of calculating the parameter for assessing the safety state of a storage facility for light hydrocarbons for the considered LPGS before and after making space-planning changes according to variant 13 .

= After making space-planning changes

=Without making space-planning changes

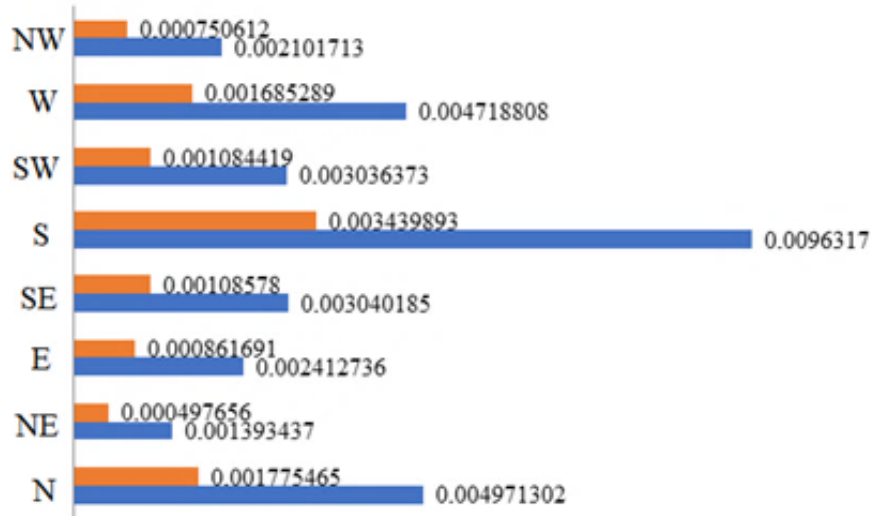

Figure 8: Comparison of the Ks parameter values for the LPGS before and after making space-planning changes (according to variant 13)

As can be seen from Figure 8, the introduction of space-planning changes can lead to a decrease in the parameter value $\mathrm{K}_{\mathrm{s}}$ by reducing the size of stagnation zones. In turn, decisions of an organisational and technical nature are an important factor. In particular, due to the refusal to carry out hot work during the technical examination of gas cylinders on the site of the facility (refusal of hot work or transferring them outside the territory of the enterprise). The probability of the ignition source appearance and, as a consequence, the value of $\mathrm{K}_{\mathrm{s}}$ for the southward wind decreases by 2.2 times (Figures 9,10 ).

As can be seen from Figure 10, in the case of joint implementation of the proposed space-planning, organisational and technical changes, the parameter value Ks decreases in the range from 2.8 to 6.4 times, depending on the wind direction. In particular, for the southward wind, the parameter value is reduced 6.4 times from 0.0077 to 0.0012 .



Figure 9: Comparison of $K_{s}$ parameter values for LPGS before and after making organisational and technical changes

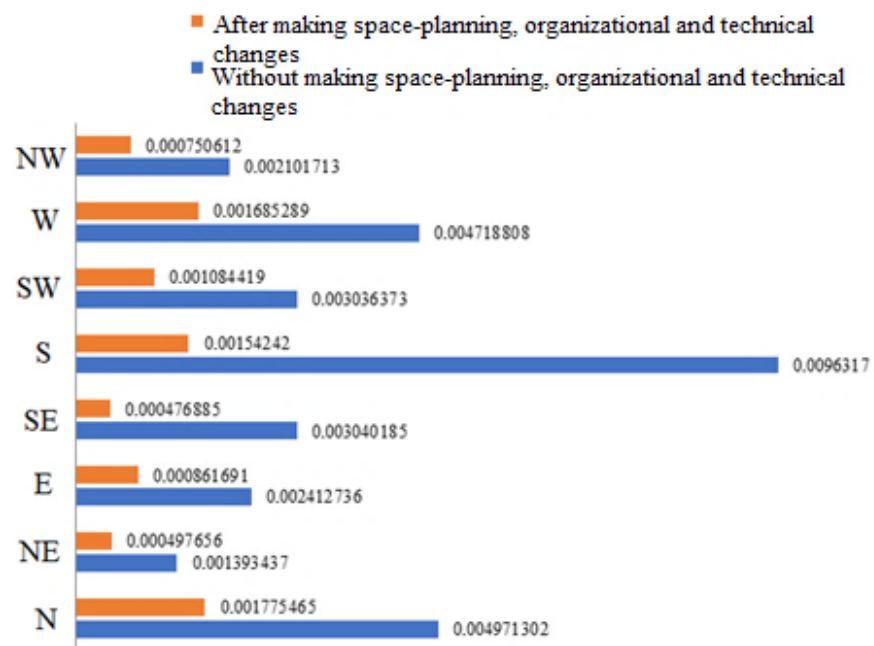

Figure 10: Comparison of the $K_{s}$ parameter values for the LPGS before and after the introduction of space-planning and organisational and technical changes

Stage 14 . Checking the safety status of the entire facility before and after making changes is carried out similarly to Stage 10. For the considered facility, the value of the resulting parameter $\mathrm{K}_{\mathrm{r}}$ decreased by 3.5 times from 0.0036 to 0.00104 , which indicates the effectiveness of 
the implemented measures.

Stage 15. If, after a complex of space-planning changes, it is required to position the object relative to the wind direction, then proceed to the implementation of Stage 9. The result of the safety assessment of the tank field in emergency situations should be a decision on the sufficiency of the implemented safety measures (stage 7).

\section{CONCLUSIONS}

Hence, computational modelling of the formation of probable stagnation zones with various space-planning solutions by using a three-dimensional modelling system and a finite volume method has been carried out. It was found that for sites of tank farms with light hydrocarbons in the oil and gas industry, the most effective measures are to increase the height of the tanks, reduce the angle of attack to the horizontal axis of the tank, and abandon the railroad embankment by laying rails at ground level.

A parameter has been developed for assessing the safety state of a light hydrocarbon storage facility (Ks) for calculating the optimal location of structures and their structural changes. It was found that by introducing space-planning, and organisational and technical changes aimed at reducing the size of air stagnation zones and reducing the likelihood of an ignition source, it is possible to increase safety by at least 2.8 times.

For the first time, a methodology for assessing the safety of storage facilities for light hydrocarbons in emergency situations has been developed and scientifically substantiated. It allows to conduct a comprehensive assessment of stagnation zones using three-dimensional modelling systems and select the most effective safety solution at all stages of the object's life cycle. The developed methodology and algorithm for it take into account the space-planning features of the object and the likelihood of a fuel-air mix ignition. The method and algorithm have been tested for the simulation object (LPG tank farm).

\section{REFERENCES}

1. Fu, H.-R., Wang, F., Zhang, J. (2015). A stable zinc-4-carboxypyrazole framework with high uptake and selectivity of light hydrocarbons. Dalton Transactions, vol. 44, no. 6, 2893-2896, DOI: 10.1039/ c4dt03594a.

2. Huang, P., Chen, C., Wu, M., Jiang, F., Hong, M. (2019). An indium-organic framework for the efficient storage of light hydrocarbons and selective removal of organic dyes. Dalton Transactions, vol. 48, no. 17, 5527-5533, DOI: 10.1039/c9dt00902g.

3. Anderson, J.S., Romanak, K.D., Meckel, T.A. (2018). Assessment of shallow subsea hydrocarbons as a proxy for leakage at offshore geologic $\mathrm{CO} 2$ storage sites. International Journal of Greenhouse Gas Control, vol. 74, 19-27, DOI: 10.1016/j.ijggc.2018.04.010.
4. Vasilyev, A.O., Shemanin, V.G., Chartiy, P.V. (2011). IR detector for hydrocarbons concentration measurement in emissions during petroleum and oil products storage and transportation. Proc. SPIE 8155, Infrared Sensors, Devices, and Applications; and Single Photon Imaging II, 81550T (16 September 2011), DOI: 10.1117/12.893371

5. Anderson, J., Romanak, K., Alfi, M., Hovorka, S. (2019). Light hydrocarbon and noble gas migration as an analogue for potential CO2 leakage: numerical simulations and field data from three hydrocarbon systems. Greenhouse Gases: Science and Technology, vol. 9, no. 2, 226-244, DOI: 10.1002/ghg.1841.

6. Zhao, X., Gong, G., Wu, S. (2018). Effect of storage time and temperature on parent and oxygenated polycyclic aromatic hydrocarbons in crude and refined vegetable oils. Food Chemistry, vol. 239, 781788, DOI: 10.1016/j.foodchem.2017.07.016.

7. Gong, G., Wu, S., Wu, X. (2018). Influences of light intensity and $\beta$-carotene on polycyclic aromatic hydrocarbons and aldehydes in vegetable oil: a case study using palm oil. Journal of Agricultural and Food Chemistry, vol. 66, no. 42, 11124-11132, DOI: 10.1021/acs.jafc.8b04096.

8. Cañipa-Morales, N.K., Galán-Vidal, C.A., Guzmán-Vega, M.A., Jarvie, D.M. (2003). Effect of evaporation on C7 light hydrocarbon parameters. Organic Geochemistry, vol. 34, no. 6, 813-826, DOI: 10.1016/ S0146-6380(03)00002-0.

9. Iaiani, M., Casson Moreno, V., Reniers, G., Tugnoli, A., Cozzani, V. (2021). Analysis of events involving the intentional release of hazardous substances from industrial facilities. Reliability Engineering and System Safety, vol. 212, article number 107593, DOI: 10.1016/j.ress.2021.107593.

10. Lauritsen, H., Kassold, S., Meneguolo, R., Furre, A. (2018). Assessing potential influence of nearby hydrocarbon production on $\mathrm{CO} 2$ storage at Smeaheia. Fifth CO2 Geological Storage Workshop 2018, p. 1-5, DOI: 10.3997/2214-4609.201802970.

11. Belmabkhout, Y., Mouttaki, H., Eubank, J.F., Guillerm, V., Eddaoudi, M. (2014). Effect of pendant isophthalic acid moieties on the adsorption properties of light hydrocarbons in HKUST-1-like tbo -MOFs: Application to methane purification and storage. RSC Advances, vol. 4, no. 109, 63855-63859, DOI: 10.1039/c4ra12432d.

12. Liu, X., Fan, W., Zhang, M., Li, G., Liu, H., Sun, D., Guo, W. (2018). Enhancing light hydrocarbon storage and separation through introducing Lewis basic nitrogen sites within a carboxylate-decorated copper-organic framework. Materials Chemistry Frontiers, vol. 2, no. 6, 1146-1154, DOI: 10.1039/ c8qm00105g. 
13. Fan, W., Liu, X., Wang, X., Li, Y., Xing, C., Wang, Y., Sun, D. (2018). A fluorine-functionalized microporous In-MOF with high physicochemical stability for light hydrocarbon storage and separation. Inorganic Chemistry Frontiers, vol. 5, no. 10, 2445-2449, DOI: 10.1039/c8qi00652k.

14. Kanazawa, T. (2004). Development of hydrocarbon adsorbents, oxygen storage materials for three-way catalysts and NOx storage-reduction catalyst. Catalysis Today, vol. 96, no. 3, 171-177, DOI: 10.1016/j. cattod.2004.06.119.

15. Chen, B. (2017). An ultrastable and easily regenerated HOF for the selective storage and separation of light hydrocarbons. Science China Chemistry, vol. 60, no. 6, 683-684, DOI: 10.1007/s11426-017-90459.

16. Liu, X., Li, X., Li, J., Li, G., Guo, S., Zhu, H., Guo, W. (2018). Anionic NbO-type copper organic framework decorated with carboxylate groups for light hydrocarbons separation under ambient conditions. Journal of Materials Science, vol. 53, 8866-8877, DOI: 10.1007/s10853-018-2155-1.

17. Fan, W., Wang, X., Zhang, X., Liu, X., Wang, Y., Kang, Z., Sun, D. (2019). Fine-tuning the pore environment of the microporous Cu-MOF for high propylene storage and efficient separation of light hydrocarbons. ACS Central Science, vol. 5, no. 7, 1261-1268, DOI: 10.1021/acscentsci.9b00423.
18. Omelchuk, M.V. (2017). Scientific substantiation of the methodology for assessing the safety of storage facilities for light hydrocarbons in emergency situations. Ufa State Oil Technical University, Ufa.

19. Permyakov, V.N., Parfenov, V.G., Omelchuk, M.V. (2015). Methodology for assessing the stability of storage facilities for liquefied hydrocarbon gases. Safety and Emergency Issues, vol. 6, 73-79.

20. Wang, Y., Wang, X., Wang, X., Zhang, X., Fan, W., Liu, D., Sun, D. (2019). Effect of functional groups on the adsorption of light hydrocarbons in FMJtype metal-organic frameworks. Crystal Growth and Design, vol. 19, no. 2, 832-838, DOI: 10.1021/acs. cgd.8b01403.

21. Wang, J., Elsworth, D. (2020). Fracture penetration and proppant transport in gas- and foam-fracturing. Journal of Natural Gas Science and Engineering, vol. 77, article number 103269, DOI: 10.1016/j. jngse.2020.103269.

22. Fu, H.-R., Zhang, J. (2015). Flexible porous zinc-pyrazole-adenine framework for hysteretic sorption of light hydrocarbons. Crystal Growth and Design, vol. 15, no. 3, 1210-1213, DOI: 10.1021/cg5016093. 